\title{
IPL Team Performance Analysis: A Multi- Criteria Group Decision Approach in Fuzzy Environment
}

\author{
Pabitra Kumar Dey \\ Department of Computer Application, Dr. B. C. Roy Engineering College, Durgapur-06, India \\ E-mail: dey_pabitra@yahoo.co.in \\ Dipendra Nath Ghosh \\ Department of Computer Science \& Engineering, Dr. B. C. Roy Engineering College, Durgapur-06, India \\ E-mail: ghoshdipen2003@yahoo.co.in
}

\author{
Abhoy Chand Mondal \\ Department of Computer Science, University of Burdwan, Burdwan, India \\ E-mail: abhoy_mondal@yahoo.co.in
}

\begin{abstract}
Now a day Cricket is one of the most popular sports around the world. Twenty-20 cricket is the most popular entertaining game in last eight to ten years among different formats of cricket. Indian Premier League (IPL) plays vital role to upturn the status of Twenty-20 cricket. This paper aims to analysis the team performances during first six sessions of IPL in the field of sports Data Mining. The proposed work deals with five different multi-criteria techniques and two group decision analysis in fuzzy environment to handle the imprecise and ambiguous data. The result shows that proposed model yields more realistic way to judge the team's performance and every time it produces the accurate performance appraisal.
\end{abstract}

Index Terms - Gaussian Fuzzy-AHP, Group Decision, Spearman Correlation coefficient, Kendall Correlation coefficient, Performance Appraisal Introduction.

\section{INTRODUCTION}

In the early 70's Multi-Criteria Decision Analysis (MCDA) was introduced as a promising and important field in data mining for both quantitative and qualitative evaluation criteria together to take truthful decision. Kavita Devi et al [1] used MCDA as a tool to solve problems for selection from a limited number of alternatives, involves sorting and ranking. The interattribute and intra-attribute comparison of MCDA was proposed by [2]. Some of the commonly used MCDA techniques like Weighted Sum Method (WSM), Technique for Order Preference by Similarity to Ideal Solution (TOPSIS), Analytical Hierarchy Process (AHP), PROMETHEE, ELECTRE etc was described in [3]. AHP is a pair-wise comparison method that involves structuring multiple choice criteria into a hierarchy for assessing the relative importance of these criteria developed by Thomas L. Saaty in early 80 's [4, 5]. TOPSIS, based on the idea that the chosen alternative should have the shortest distance from the positive ideal solution and on the other side the farthest distance of the negative ideal was first developed by Hwang and Yoon [6]. COmplex PRoportional ASsessment (COPRAS) method, used for multi-criteria evaluation of both maximizing and minimizing criteria values was first developed by Kaklauskas in 1996 [7]. In 1998, [8] initiated a new technique known as VIKOR for determining the compromise solution for a problem with contrasting criteria to reach the final solution. Brans and Vincke [9] proposed a new technique named as Preference Ranking Organization METHod for Enrichment of Evaluations (PROMETHEE) at the beginning of the 1980s. Several MCDA provide different ranking for the same problem which is the major shortcomings of MCDA. Earlier we proposed a new mathematical model namely as Modified Group Decision Analysis (MGDA) [10] to overcome the main limitation of MCDA. Now in this paper we introduce Gaussian Fuzzy numbers to handle the uncertainty and ambiguous decision of expert opinion with five methods together to form a new model which is more accurate than the earlier MGDA technique.

People of India are fascinated with the game of cricket among all the games played in India. Twenty-20, the shorter format of cricket is the most popular entertainment sports in India. IPL was initiated in the year 2008 with 8 teams by the Board for Control of Cricket in India (BCCI) [11, 12]. IPL provides a great platform for every cricketers to fulfill their dreams. A graphical display for comparing the performances of bowlers, batsmen and all-rounders have been presented by Paul J.van.Staden [13]. The valuation of players in the IPL has been calculated by David Parker and et al. [14]. H.H. Lemmer proposed several techniques for assessing the performance of bowlers, batsmen [15, 16, 17]. Individual performance of the players and the overall performance of the teams are easily measured by our proposed methodology. 
The paper is organized as follows: Section 2 focuses on the different terminologies that are used to judge the players and the dataset preparation for team performance analysis. Section 3 discusses about the techniques used and discussed the proposed methodology. Result and Discussion are carried out on section 4. In section 5 group decision techniques are discussed. Finally, section 6 concludes the paper.

\section{TERMINOLOGY USED \& PREPARATION OF DATASET}

At first we collect the original dataset from open source of information for the last six year of IPL starting from 2008 and ended with the year 2013. The table 1 displays single dataset of the teams for the starting year 2008.

Table 1. Dataset of the team in IPL for the year 2008.

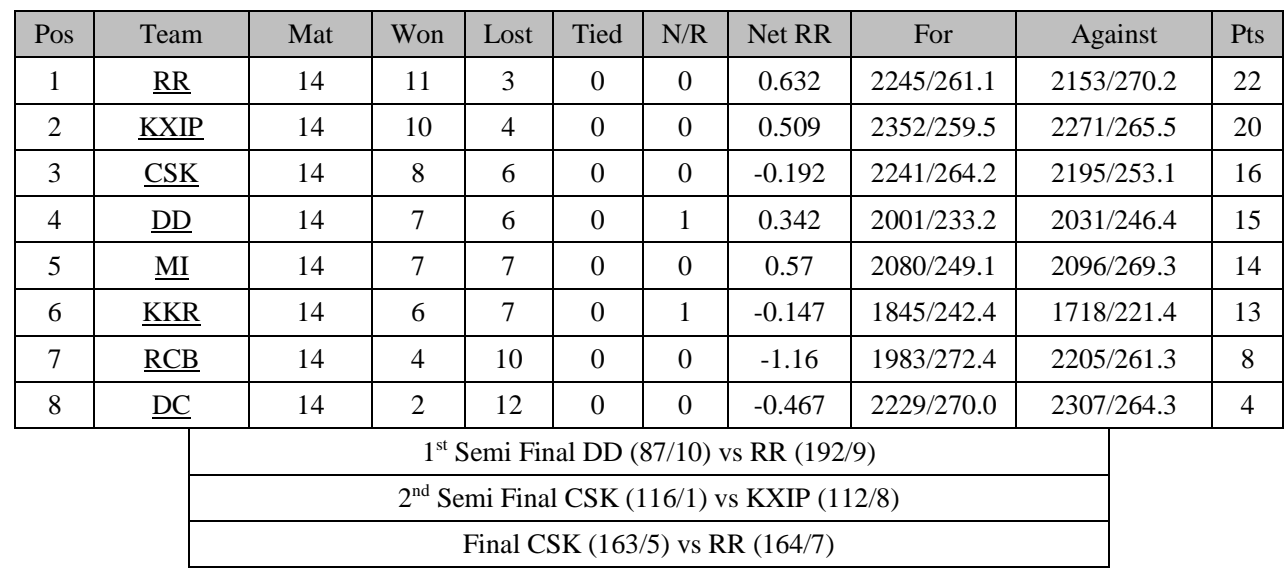

Several multiple criteria are involved to judge a team's performance accurately and we consider the following multiple criteria for team performance analysis-

Mat - Total match played by a team in IPL from 2008 to 2013.

Won - (No. of matches won by a team) / (Total match played).

Lost - (No. of matches lost by a team) / (Total match played).

For $(\boldsymbol{R R})$ - (Total runs made by a team / Total no. of overs taken to make the runs).

Against (RR) - (Total runs given by a team / Total no. of overs bowled).
$\boldsymbol{N R R}$ - For (RR) - Against (RR).

Margin-Team won by how many runs or by how many wickets in a winning match from the losing team.

WM - Total Margin / Total match played.

$\boldsymbol{A} \boldsymbol{W A} \boldsymbol{Y}$ - Total match won in away condition / Total match played.

Important match - Quarter Final, Semi Final, Final matches are considered as important matches.

IMP - (Total win of important match $)-($ Total loss of important match).

With the above multiple criteria we prepared the overall team dataset from year 2008 to year 2013 is as follows in the table 2 :

Table 2. Prepared Dataset from 2008 to 2013.

\begin{tabular}{|c|c|c|c|c|c|c|c|c|}
\hline Team ID & Team & Mat & won & lost & NRR & WM & AWAY & IMP \\
\hline 1 & CSK & 100 & 0.59 & 0.39 & 0.45 & 2.28 & 0.32 & 4 \\
\hline 2 & DC/SRH & 93 & 0.42 & 0.57 & -0.16 & 1.37 & 0.29 & -1 \\
\hline 3 & DD & 92 & 0.46 & 0.52 & -0.12 & 2.08 & 0.3 & -4 \\
\hline 4 & KKR & 91 & 0.46 & 0.51 & -0.03 & 1.69 & 0.24 & 1 \\
\hline 5 & KXIP & 89 & 0.49 & 0.51 & -0.08 & 1.86 & 0.28 & -1 \\
\hline 6 & MI & 96 & 0.58 & 0.41 & 0.39 & 2.55 & 0.28 & 0 \\
\hline 7 & RCB & 95 & 0.51 & 0.47 & -0.06 & 2.1 & 0.29 & -1 \\
\hline 8 & RR & 92 & 0.53 & 0.45 & 0.11 & 2.4 & 0.26 & 2 \\
\hline 9 & PWI & 46 & 0.3 & 0.7 & -0.62 & 0.94 & 0.17 & -6 \\
\hline 10 & KTK & 14 & 0.29 & 0.64 & -0.13 & 1.59 & 0.21 & -6 \\
\hline
\end{tabular}

\section{TEChNIQUES USED \& Proposed Methodology}

Some useful techniques are defined before we describe our proposed methodology for measuring the team performance. Analytical Hierarchy Process (AHP) is used to calculate the relative importance between the criterion based on expert opinion with the help of Saaty's 9-point linear scale and the detailed steps of AHP was described in our previous work named as "Modified Group Decision Algorithm for Performance Appraisal of Indian

Premier League Cricketers" [10]. Saaty's AHP method was modified by introducing the fuzzy analysis by 
Chang's in 1992 [18] and the main drawback of Chang's extent analysis is that the degree of possibility of some criteria was zero. To overcome this limitation Hesham A and et. al. used Gaussian fuzzy number insist of triangular fuzzy number [19] and we modified the steps of Hesham's Gaussian extent to calculate the relative importance between criteria with the help of the following flowchart:

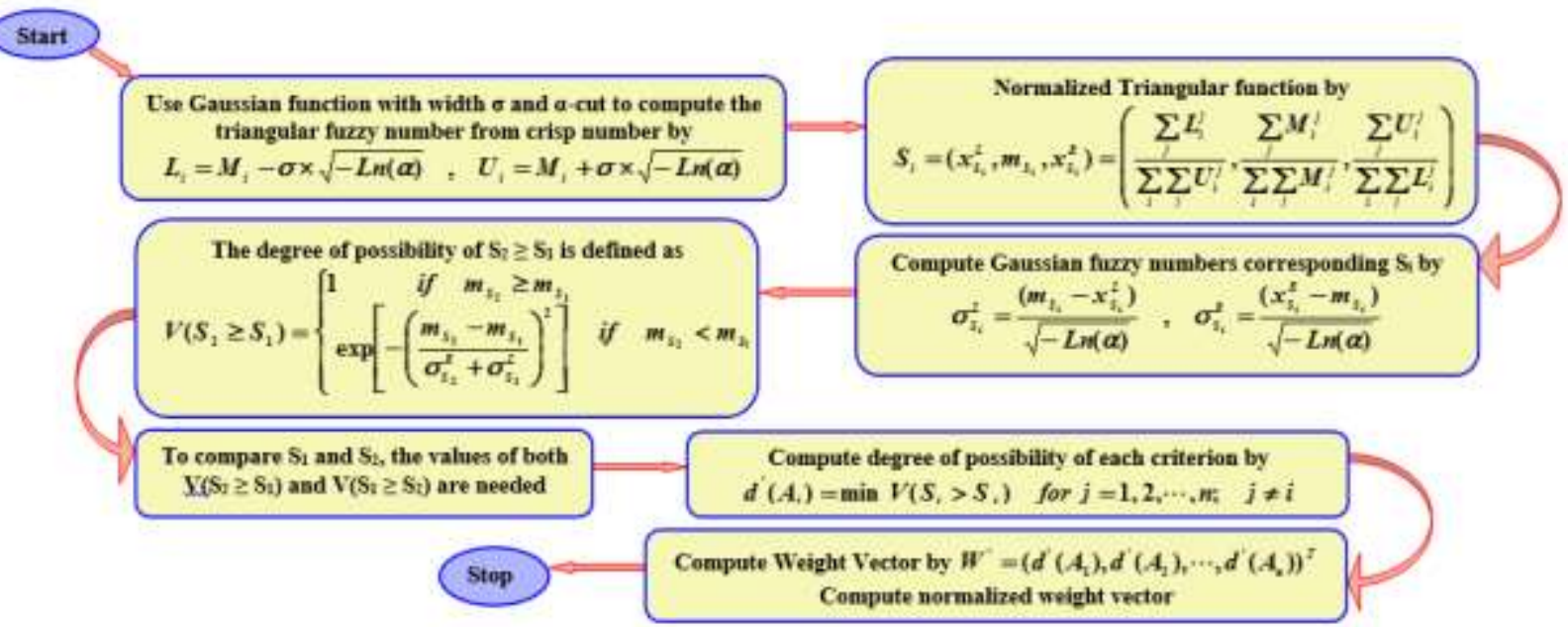

Fig. 1. Flowchart of Gaussian Fuzzy-AHP.

Several MCDM methods like WSM, TOPSIS, COPRAS, VIKOR and PROMETHEE are used in our proposed methodology. The detailed steps of WSM, TOPSIS, COPRAS, VIKOR are described in our previous published research work named "Modified Group Decision Algorithm for Performance Appraisal of Indian Premier League Cricketers" [20]. The detailed steps of PROMETHEE are described by the following flowchart.

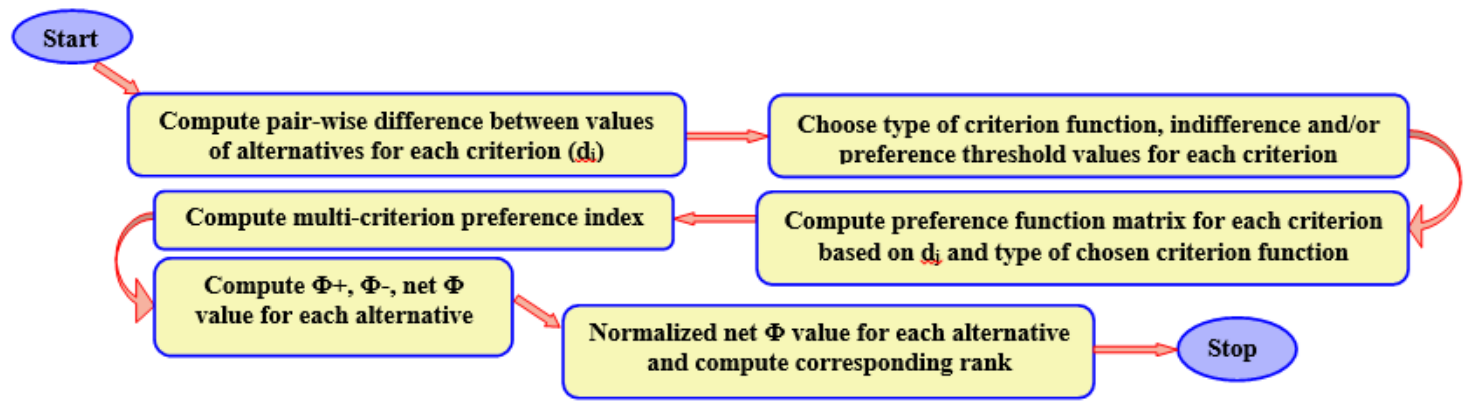

Fig. 2. Flowchart of PROMETHEE.

With the help of above techniques, Spearman and Kendall correlation and coefficient ranking method to calculate group decision multi criteria analysis we propose a new technique which provides the accurate result in every case and our proposed methodology is described in the following flowchart:

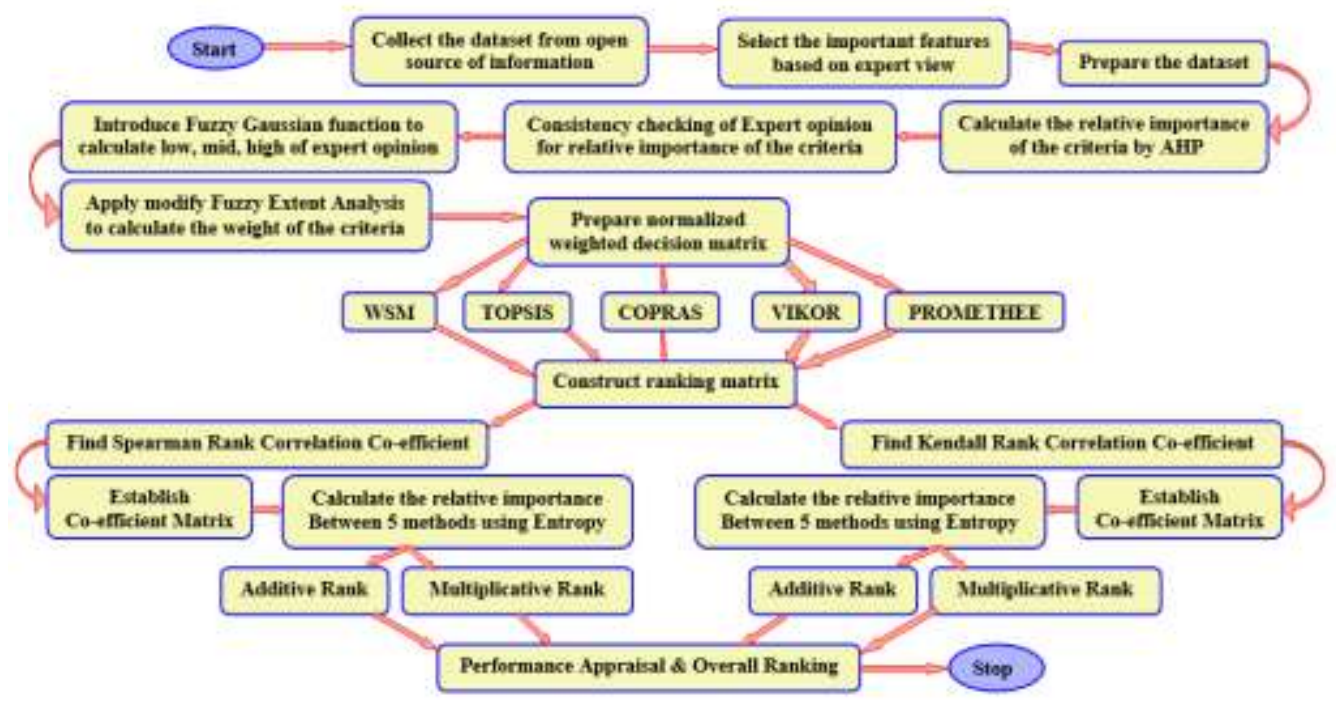

Fig. 3. Proposed Methodology. 


\section{RESULT \& DISCUSSION}

After prepare the pay-off matrix we calculate the weights of the attribute by AHP. Then Gaussian fuzzy membership function is presented in [19] to overcome Saaty 9 point linear scale into fuzzy scale by considering original AHP decision input into low, mid, high decision and then we develop one modified technique of Chang's extent analysis [18] to calculate more accurate importance relative between the attributes. The weights of the attribute calculating by AHP and Fuzzy-AHP

(FAHP) are shown in table 3 and ranking of different method are shown in table 4 . The detailed result is shown in the appendix section.

Table 3. Attributes weight by AHP and Fuzzy-AHP.

\begin{tabular}{|c|c|c|c|c|c|c|c|}
\hline & Mat & won & lost & NRR & WM & AWAY & IMP \\
\hline AHP & $\mathbf{0 . 0 6 7}$ & $\mathbf{0 . 2 5 9}$ & $\mathbf{0 . 2 1 4}$ & $\mathbf{0 . 1 5 7}$ & $\mathbf{0 . 1 2 8}$ & $\mathbf{0 . 0 7 6}$ & $\mathbf{0 . 1 0 0}$ \\
\hline FAHP & $\mathbf{0 . 0 2 3}$ & $\mathbf{0 . 2 9 8}$ & $\mathbf{0 . 2 7 2}$ & $\mathbf{0 . 1 7 7}$ & $\mathbf{0 . 1 2 5}$ & $\mathbf{0 . 0 3 3}$ & $\mathbf{0 . 0 7 2}$ \\
\hline
\end{tabular}

Table 4. Ranking of different method.

\begin{tabular}{|c|c|c|c|c|c|c|c|c|c|c|c|}
\hline ID & Team & Prome -thee & Rank & WSM & Rank & Topsis & Rank & Copras & Rank & Vikor & Rank \\
\hline 1 & CSK & 0.343 & 1 & 3.2451 & 1 & 0.9776 & 1 & -0.4733 & 1 & 0 & 1 \\
\hline 2 & DC /SRH & -0.0481 & 8 & 2.4997 & 6 & 0.4334 & 8 & 0.3544 & 9 & 0.5537 & 8 \\
\hline 3 & DD & -0.0111 & 7 & 2.3552 & 8 & 0.4632 & 7 & 0.3535 & 8 & 0.4047 & 6 \\
\hline 4 & KKR & 0.0172 & 6 & 2.6547 & 4 & 0.5656 & 4 & 0.1689 & 4 & 0.4047 & 6 \\
\hline 5 & KXIP & 0.0201 & 5 & 2.4873 & 7 & 0.5215 & 6 & 0.266 & 6 & 0.3156 & 5 \\
\hline 6 & MI & 0.2753 & 2 & 2.8894 & 2 & 0.8793 & 2 & -0.3487 & 2 & 0.0292 & 2 \\
\hline 7 & RCB & 0.0629 & 4 & 2.6543 & 5 & 0.5485 & 5 & 0.2495 & 5 & 0.2374 & 4 \\
\hline 8 & RR & 0.185 & 3 & 2.8684 & 3 & 0.7067 & 3 & -0.0071 & 3 & 0.1445 & 3 \\
\hline 9 & PWI & -0.5066 & 10 & 0.9192 & 9 & 0.0138 & 10 & 1 & 10 & 1 & 9 \\
\hline 10 & KTK & -0.3377 & 9 & 0.3332 & 10 & 0.39 & 9 & 0.3468 & 7 & 1.0371 & 10 \\
\hline
\end{tabular}

\section{GROUP DISCUSSION}

Spearman Co-relation Co-efficient and Kendall Corelation Co-efficient between the methods are shown in table 5:

Table 5. Correlation Coefficient Ranking by Spearman and Kendall
\begin{tabular}{|c|c|c|c|c|c|}
\hline Spearman & Promethee & Wsm & Topsis & Copras & Vikor \\
\hline $\begin{array}{c}\text { PROM- } \\
\text { ETHEE }\end{array}$ & 1 & 0.8667 & 0.95 & 0.9 & 0.975 \\
\hline WSM & 0.8667 & 1 & 0.9333 & 0.8333 & 0.8583 \\
\hline TOPSIS & 0.95 & 0.9333 & 1 & 0.95 & 0.925 \\
\hline COPRAS & 0.9 & 0.8333 & 0.95 & 1 & 0.825 \\
\hline VIKOR & 0.975 & 0.8583 & 0.925 & 0.825 & 1 \\
\hline Kendall & Promethee & Wsm & Topsis & Copras & Vikor \\
\hline $\begin{array}{c}\text { PROM- } \\
\text { ETHEE }\end{array}$ & 1 & 0.7778 & 0.9111 & 0.8222 & 0.9556 \\
\hline WSM & 0.7778 & 1 & 0.8667 & 0.7778 & 0.8222 \\
\hline TOPSIS & 0.9111 & 0.8667 & 1 & 0.9111 & 0.8667 \\
\hline COPRAS & 0.8222 & 0.7778 & 0.9111 & 1 & 0.7778 \\
\hline VIKOR & 0.9111 & 0.7778 & 0.8222 & 0.7333 & 1 \\
\hline
\end{tabular}

Calculate the relative closeness between the methods by entropy in both the correlation coefficient methods which is shown in the table 6 .
Table 6. Relative Closeness between the methods

\begin{tabular}{|c|c|c|c|c|c|}
\hline & $\begin{array}{c}\text { PROM- } \\
\text { ETHEE }\end{array}$ & WSM & TOPSIS & COPRAS & VIKOR \\
\hline Spearman & 0.2015 & 0.1980 & 0.2026 & 0.1983 & 0.1996 \\
\hline Kendall & 0.2019 & 0.1979 & 0.2037 & 0.1987 & 0.1978 \\
\hline
\end{tabular}

Calculate Additive \& Multiplicative Ranking of the teams according Spearman and Kendall Correlation Coefficient are shown in the table 7:

Table 7. Additive and Multiplicative Ranking of the teams

\begin{tabular}{|c|c|c|c|c|c|}
\cline { 3 - 6 } \multicolumn{2}{c|}{} & \multicolumn{2}{c|}{ Kendall } & \multicolumn{2}{c|}{ Spearman } \\
\hline $\begin{array}{c}\text { Team } \\
\text { ID }\end{array}$ & Team & $\begin{array}{c}\text { Add. } \\
\text { Rank }\end{array}$ & $\begin{array}{c}\text { Mul. } \\
\text { Rank }\end{array}$ & $\begin{array}{c}\text { Add. } \\
\text { Rank }\end{array}$ & $\begin{array}{c}\text { Mul. } \\
\text { Rank }\end{array}$ \\
\hline 1 & CSK & 1 & 1 & 1 & 1 \\
\hline 2 & DC/SRH & 8 & 8 & 8 & 8 \\
\hline 3 & DD & 7 & 7 & 7 & 7 \\
\hline 4 & KKR & 5 & 5 & 5 & 5 \\
\hline 5 & KXIP & 6 & 6 & 6 & 6 \\
\hline 6 & MI & 2 & 2 & 2 & 2 \\
\hline 7 & RCB & 4 & 4 & 4 & 4 \\
\hline 8 & RR & 3 & 3 & 3 & 3 \\
\hline 9 & PWI & 10 & 10 & 10 & 10 \\
\hline 10 & KTK & 9 & 9 & 9 & 9 \\
\hline
\end{tabular}


The ultimate ranking of the teams is same for additive ranking and multiplicative ranking in both Spearman and Kendall correlation coefficient which confirm the fruitfulness of our proposed method and this new model overcome the main drawbacks of MCDM method that different techniques provide different ranking for the same set of problems.

According our new model it is very much clear that in all six years of IPL, the performance of CSK is very decent and consistent and after that the performance of $\mathrm{MI}$ is good. The overall performance of DC/SRH is not at all up to the mark although DC/SRH won the IPL cup in 2009. RCB still not win the title but its performance is very much consistent and they done well from the starting of IPL.

\section{CONCLUSION}

This article offers emerging idea in the field of multi criteria decision analysis in fuzzy environment by integrating few multi criteria techniques in a single model. This proposed work eliminate the main drawback of multi-criteria decision analysis that is different multi criteria methods provide different ranking for the same problem with same multiple attributes and same multiple alternatives although same decision maker.

Cricket team performance measurement is done with this new model to get the precise result every time. Fuzzy membership handles the uncertainty and improper judgment of any linear scale pair-wise comparison between alternatives or attributes.

In every step of this mathematical model we check the accuracy in terms of consistency checking or correlation between intermediate methods or calculate the overall additive or multiplicative ranking. In this model both Spearman and Kendall correlation coefficient methods are used to find the relative closeness between the different MCDM methods and the result of this work shows that the new model is scientifically and mathematically error free and produce precise outcome in every time.

This new model helps the decision maker to make their error free decision in very systematic way irrespective of any specific field of multi criteria.

\section{REFERENCES}

[1] Devi, K., Yadav, S.P. and Kumar, S., Extension of fuzzy TOPSIS method based on vague sets, International Journal of Cmputaional Cognition, Vol. 7(4), pp:58-62, 2009.

[2] Carlsson, C., and Fuller, R., (1996). Fuzzy multiple criteria decision making: Recent development 139-153.

[3] Muralidharan C., (2000), Application of Analytic Hierarchy Process (AHP) in materials and human resource management under group decision making environment, Unpublished Ph.D. Thesis, Annamalai University.

[4] Saaty, T. L., The Analytic Hierarchy Process, McGraw-Hill, New York, 1980.

[5] Saaty, T. L., "Priority Setting in Complex Problems," IEEE Transactions on Engineering Management, Vol.30, No.3, pp.140-155, 1983.
[6] Hwang, C.L., Yoon, K., "Multiple Attribute DecisionMaking Methods and Applications", Springer, BerlinHeidelberg, 1981.

[7] Kaklauskas, A.,. Zavadskas, E.K., Multicriteria Evaluation of Building. Vilnius: Technika. (1996).

[8] Opricovic, S., Multicriteria Optimization of Civil Engineering Systems, Faculty of CivilEngineering, Belgrade (1998).

[9] Brans, J.P. and Vincke, P., "A preference ranking organisation method: The PROMETHEE method for MCDM". Management Science. (1985).

[10] Dey, P.K., Ghosh, D.N. and Mondal, A.C., "Modified Group Decision Algorithm for Performance Appraisal of Indian Premier League Cricketers", in WSEAS Transactions on Information Science and Applications (WSEAS- ToISA), E-ISSN: 2224-3402, Vol. 10, Issue 10, October-2013, pp: 325-333.

[11] Blog: http://premierleaguecricket.in

[12] http://en.wikipedia.org/wiki/Indian_Premier_League

[13] Staden, P.J. van, "Comparison of Bowlers, Batsmen and All-rounders in Cricket using Graphical Displays", Technical Report of University of Pretoria, 08 01, ISBN: 9781868547333.

[14] Parker, D., Burns, P. and Natarajan, H., "Player Valuations in the IndianPremier League", Frontier EconomicsOctober 2008.

[15] Lemmer, H.H., "The Combined Bowling Rate as a Measure of Bowling Performance in Cricket", South African Journal for Research in Sport, Physical Education and Recreation, Vol. 24, No. 2, pp.37-44, 2002.

[16] Lemmer, H.H., "A Measure for the Batting Performance of Cricket Players", South African Journal for Research in Sport, Physical Education and Recreation, Vol. 26, No. 1, pp.55-64, 2004.

[17] Lemmer, H.H., "The Allocation of Weights in the Calculation of Batting and Bowling Performance Measures", South African Journal for Research in Sport, Physical Education and Recreation, Vol. 29, No. 2, pp.7585, 2007.

[18] Chang D. Extent analysis and synthetic decision. Optimization techniques and applications, vol. 1. Singapore: World Scientific;1992, p. 352.

[19] Hefny, H.A., Elsayed, H.M., Aly, H.F., "Fuzzy multicriteria decision making model for different scenarios of electrical power generation in Egypt", Egyptian Informatics Journal (2013) Vol. 14, pp.125-133, 2013.

[20] IPL, http://iplt20.com/.

[21] Spearman, C. (1904). "The proof and measurement of association between two things". Amer. J. Psychol. 15: 72101. doi:10.2307/1412159.

[22] Kendall, M.G., Rank correlation methods (4th ed.). London: Griffin. ISBN 978-0-852-6419-96. OCLC 136868. (1970). 
APPENDIX

Table 8. AHP Pair-wise comparison table

\begin{tabular}{|c|c|c|c|c|c|c|c|c|}
\hline Criteria & Mat & won & lost & NRR & WM & AWAY & IMP & $\mathbf{W}$ \\
\hline MAT & 1.000 & 0.250 & 0.333 & 0.500 & 0.500 & 1.000 & 0.500 & 0.0666 \\
\hline WON & 4.000 & 1.000 & 1.000 & 2.000 & 2.000 & 3.000 & 3.000 & 0.2586 \\
\hline LOST & 3.000 & 1.000 & 1.000 & 1.000 & 2.000 & 3.000 & 2.000 & 0.2135 \\
\hline NRR & 2.000 & 0.500 & 1.000 & 1.000 & 1.000 & 2.000 & 2.000 & 0.1569 \\
\hline WM & 2.000 & 0.500 & 0.500 & 1.000 & 1.000 & 2.000 & 1.000 & 0.1280 \\
\hline Away & 1.000 & 0.333 & 0.333 & 0.500 & 0.500 & 1.000 & 1.000 & 0.0764 \\
\hline IMP & 2.000 & 0.333 & 0.500 & 0.500 & 1.000 & 1.000 & 1.000 & 0.1000 \\
\hline
\end{tabular}

Table 9. FAHP (Normalized Triangular Function with Gaussian Fuzzy Number)

\begin{tabular}{|c|c|c|c|c|c|c|c|c|}
\hline $\boldsymbol{\alpha}=\mathbf{0 . 1}, \mathbf{= 0 . 2 5}$ & LOW & MID & HIGH & LOW & MID & HIGH & Si- L & Si- R \\
\hline MAT & 1.428 & 4.083 & 6.739 & 0.018 & 0.066 & 0.157 & 0.032 & 0.060 \\
\hline WON & 13.345 & 16.000 & 18.655 & 0.166 & 0.260 & 0.434 & 0.062 & 0.115 \\
\hline LOST & 10.345 & 13.000 & 15.655 & 0.129 & 0.211 & 0.364 & 0.054 & 0.101 \\
\hline NRR & 6.845 & 9.500 & 12.155 & 0.085 & 0.154 & 0.283 & 0.045 & 0.085 \\
\hline WM & 5.345 & 8.000 & 10.655 & 0.067 & 0.130 & 0.248 & 0.042 & 0.078 \\
\hline Away & 2.011 & 4.667 & 7.322 & 0.025 & 0.076 & 0.170 & 0.033 & 0.062 \\
\hline IMP & 3.678 & 6.333 & 8.989 & 0.046 & 0.103 & 0.209 & 0.038 & 0.070 \\
\hline Sum & 42.995 & 61.583 & 80.172 & & & & & \\
\hline
\end{tabular}

Table 10. FAHP (Degree of Possibility with weight Calculation)

\begin{tabular}{|c|c|c|c|c|c|c|c|c|c|c|c|}
\hline & Mat & won & lost & NRR & WM & AWAY & IMP & MIN & FAHP & AHP & Weight \\
\hline MAT & 1.000 & 0.078 & 0.197 & 0.496 & 0.674 & 0.990 & 0.868 & 0.078 & 0.023 & 0.556 & $\mathbf{0 . 0 2 7}$ \\
\hline WON & 1.000 & 1.000 & 1.000 & 1.000 & 1.000 & 1.000 & 1.000 & 1.000 & 0.298 & 0.599 & $\mathbf{0 . 3 7 0}$ \\
\hline LOST & 1.000 & 0.914 & 1.000 & 1.000 & 1.000 & 1.000 & 1.000 & 0.914 & 0.272 & 0.556 & $\mathbf{0 . 3 1 4}$ \\
\hline NRR & 1.000 & 0.594 & 0.846 & 1.000 & 1.000 & 1.000 & 1.000 & 0.594 & 0.177 & 0.545 & $\mathbf{0 . 2 0 0}$ \\
\hline WM & 1.000 & 0.419 & 0.684 & 0.962 & 1.000 & 1.000 & 1.000 & 0.419 & 0.125 & 0.036 & $\mathbf{0 . 0 0 9}$ \\
\hline Away & 1.000 & 0.110 & 0.259 & 0.588 & 0.763 & 1.000 & 0.929 & 0.110 & 0.033 & 0.036 & $\mathbf{0 . 0 0 3}$ \\
\hline IMP & 1.000 & 0.241 & 0.467 & 0.820 & 0.943 & 1.000 & 1.000 & 0.241 & 0.072 & 0.521 & $\mathbf{0 . 0 7 8}$ \\
\hline
\end{tabular}

Table 11. Spearman Correlation coefficient calculation

\begin{tabular}{|c|c|c|c|c|c|c|c|c|c|c|c|c|c|c|c|}
\hline Team & P-rank & W-rank & T-rank & C-rank & V-rank & P-W & P-T & P-C & P-V & W-T & W-C & W-V & T-C & T-V & C-V \\
\hline CSK & 1 & 1 & 1 & 1 & 1 & 0 & 0 & 0 & 0 & 0 & 0 & 0 & 0 & 0 & 0 \\
\hline DC/SRH & 8 & 6 & 8 & 9 & 8 & 4 & 0 & 1 & 0 & 4 & 9 & 4 & 1 & 0 & 1 \\
\hline DD & 7 & 8 & 7 & 8 & 6 & 1 & 0 & 1 & 1 & 1 & 0 & 4 & 1 & 1 & 4 \\
\hline KKR & 6 & 4 & 4 & 4 & 6 & 4 & 4 & 4 & 0 & 0 & 0 & 4 & 0 & 4 & 4 \\
\hline KXIP & 5 & 7 & 6 & 6 & 5 & 4 & 1 & 1 & 0 & 1 & 1 & 4 & 0 & 1 & 1 \\
\hline MI & 2 & 2 & 2 & 2 & 2 & 0 & 0 & 0 & 0 & 0 & 0 & 0 & 0 & 0 & 0 \\
\hline RCB & 4 & 5 & 5 & 5 & 4 & 1 & 1 & 1 & 0 & 0 & 0 & 1 & 0 & 1 & 1 \\
\hline $\mathbf{R R}$ & 3 & 3 & 3 & 3 & 3 & 0 & 0 & 0 & 0 & 0 & 0 & 0 & 0 & 0 & 0 \\
\hline PWI & 10 & 9 & 10 & 10 & 9 & 1 & 0 & 0 & 1 & 1 & 1 & 0 & 0 & 1 & 1 \\
\hline KTK & 9 & 10 & 9 & 7 & 10 & 1 & 0 & 4 & 1 & 1 & 9 & 0 & 4 & 1 & 9 \\
\hline & & & & & SUM & 16 & 6 & 12 & 3 & 8 & 20 & 17 & 6 & 9 & 21 \\
\hline & & & \multicolumn{3}{|c|}{ Spearman coefficient } & 0.87 & 0.95 & 0.9 & 0.98 & 0.93 & 0.83 & 0.86 & 0.95 & 0.93 & 0.83 \\
\hline
\end{tabular}


Table 12. Kendall Correlation coefficient calculation




Authors' Profile

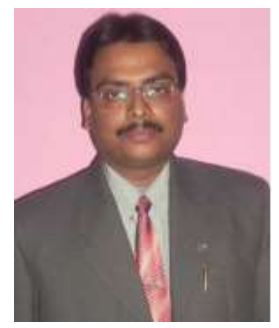

Mr. Pabitra Kumar Dey is working as an Asst. Prof. in the Dept. of Computer Application, Dr. B.C.Roy Engineering College, Durgapur, India. He was born on 10/12/1978. He obtained B.Sc.(Math Hons.) in 2000, M.C.A. in 2004 \& M.Tech.(CST) in 2011. He registered himself as a research scholar in the Dept. of Computer Science, Burdwan University. He has about more than of 10 years of Teaching Experience and 7 years of Research Experience. He has more than 20 research papers in reputed journals and conference proceedings. The broad area of his research interest is in "Soft Computing, Multi Criteria Analysis, Decision Theory, etc."



Dr. Dipendra Nath Ghosh is currently Associate Professor in the department of Computer Science \& Engineering, Dr. B.C.Roy Engineering College, Durgapur713206, W.B., India. He obtained M.Sc. in Mathematics \& M.C.A. from University of Burdwan and Ph.D. in Computer Science from that University in 2008 . He has over 10 years of teaching experience and 07 years of research experience. He is guiding M.Tech. \& Ph.D. students and has 20 research papers to his credit.

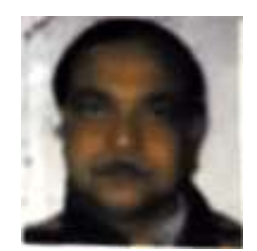

Dr. Abhoy Chand Mondal is currently Associate Professor of Department of Computer Science, Burdwan University, W.B, India. He received his B.Sc. (Mathematics Hons.) from The University of Burdwan in 1987, M.Sc. (Math) and M.C.A. from Jadavpur University, in 1989, 1992 respectively. He received his Ph.D. from Burdwan University in 2004. He has 1 year industry experience and 19 years of teaching and research experience. No. of journal paper is more than 20 .

How to cite this paper: Pabitra Kumar Dey, Dipendra Nath Ghosh, Abhoy Chand Mondal,"IPL Team Performance Analysis: A Multi-Criteria Group Decision Approach in Fuzzy Environment", International Journal of Information Technology and Computer Science(IJITCS), vol.7, no.8, pp.8-15, 2015. DOI: 10.5815/ijitcs.2015.08.02 